\title{
Determination of Silty Soil Bearing Capacity in Binzhou China
}

\author{
Zhang Yunfeng ${ }^{1,2}$, Zeng Yifan ${ }^{1}$, Liu Lanyu ${ }^{3}$, Wang Shi $^{3}$, Zhang Youlin ${ }^{3}$ and Xing Liting ${ }^{4, *}$ \\ ${ }^{1}$ College of Geoscience and Surveying Engineering, China University of Mining \& Technology, Beijing, 100083, \\ P.R. China \\ ${ }^{2}$ Shandong Provincial Geo-mineral Engineering Exploration Institute, Jinan, Shandong, 250014, P.R. China \\ ${ }^{3}$ Shandong Institute of Geological Surveying and Mapping, Jinan, Shandong, 250002, P.R. China \\ ${ }^{4}$ University of Jinan, Jinan, Shandong, 250022, P.R. China
}

\begin{abstract}
The characteristic values of bearing capacity of silty soil are determined on different basis in Binzhou area, which causes a greater difference in actual work. Based on engineering practices, a plenty of original data are counted and calculated according to standard penetration test, soil test and double bridge CPT in order to be analyzed and compared. The results show that the bearing capacity obtained from the field test data is more accurate. Standard penetration test and double bridge CPT match better to determine the bearing capacity of the silty soil. The eigenvalues of bearing capacity of silty soil is suggested to be $130 \mathrm{kPa}$. Standard penetration test and double bridge CPT should be paid more attention to the silty soil sediment in Binzhou area in the investigation work.
\end{abstract}

Keywords: Binzhou area, characteristic values of bearing capacity, in-situ test, silty soil, CPT, Standard penetration test.

\section{INTRODUCTION}

The Yellow River alluvium and sediments in Binzhou area have a large thickness and a wide range. The silty soil distributes widely, with $0 \quad-7.5 \mathrm{~m}$ depth and $0.5-6.2 \mathrm{~m}$ thickness, usually used as a bearing layer for buildings. To determine the bearing capacity of this layer, some technicians use the standard penetration testing data, while others use soil testing data. But there is a clear difference between these two results [1-3], causing a certain degree of interference for foundation design. Therefore, specific statistical analysis [4] was applied to scientifically determine the bearing capacity of silty soil, which provided a more accurate basis for foundation design and found more practical and feasible local empirical value.

\section{BASIC CHARACTERISTICS OF SILTY SOIL IN BINZHOU AREA}

The data of 674 boreholes in four power plants, obtained in the construction of large engineering investigation project, are selected for study and they have extensive representation. The silt layers in this area are alluvium, and the overall characteristics are as follows:

*Address correspondence to this author at the College of Resources and Environment, University of Jinan, Jinan, Shandong, 250022, P.R. China; Tel: +86 13969066769; Fax: +86 53188933178 ;

E-mails: xlting596@163.com; yfeng_zhang@163.com
Silty soil $\left(\mathrm{Q}_{4}{ }^{\mathrm{al}}\right)$ is brown to dark brown, slightly tight close grained, slightly wet - very wet, $0.5-6.2 \mathrm{~m}$ thickness. The physical and mechanical parameters are shown in Table 1.

\section{METHODS FOR DETERMINING BEARING CAPACITY}

\subsection{Determining Bearing Capacity of Silty Soil by} Standard Penetration Test

\subsubsection{Standard Penetration Test Data Statistics}

Standard penetration tests are performed for 181 times in the silty soil sediment. The statistical results are shown in Table 2.

\subsubsection{Calculation and Analysis of Statistical Data}

According to the statistical results, the data distribution histogram (Fig. 1) is as follows:

From the results of the statistics mentioned in Fig. (1), the results of standard penetration test mostly concentrate in the range of $3 \sim 6$, accounting for $88.9 \%$ of the total statistics. The proportion of 2, 7, 8 and 9 is a bit less. After calculating these data, according to the related literature [5], the variation coefficient $\delta=0.317$, which is greater than the theoretical upper limit of 0.3 . If numbers of $2,7,8,9$ are eliminated for their obvious deviation, the variation coefficient $\delta=0.239<0.3$ (the theoretical upper limit value of variation coefficient), then the standard value $\Phi_{\mathrm{k}}=4.215$, maximum value 6 , minimum value 3 and average value $\Phi_{\mathrm{m}}=4.356$. 
Table 1. Physical and mechanical parameters statistics.

\begin{tabular}{|c|c|c|c|c|c|c|c|}
\hline $\begin{array}{l}\text { Geotechnical } \\
\text { Name }\end{array}$ & Statistical Projects & $\begin{array}{l}\text { Natural Water } \\
\text { Content w (\%) }\end{array}$ & $\begin{array}{c}\text { Specific Gravity of } \\
\text { Soil Gs }\end{array}$ & $\begin{array}{l}\text { Natural Void } \\
\text { Ratio e }\end{array}$ & $\begin{array}{l}\text { Liquid Limit } \\
\text { wL (\%) }\end{array}$ & $\begin{array}{l}\text { Plastic Limit } \\
\text { wp(\%) }\end{array}$ & $\begin{array}{l}\text { Liquidity } \\
\text { Index IL }\end{array}$ \\
\hline \multirow{7}{*}{ Silty soil } & Statistical number & 117 & 120 & 114 & 120 & 120 & 83 \\
\hline & $\operatorname{Max}$ & 46.2 & 2.76 & 1.319 & 51.9 & 30.3 & 1.15 \\
\hline & Min & 16.7 & 2.67 & 0.481 & 21.8 & 14 & 0.33 \\
\hline & Average & 25.4 & 2.7 & 0.72 & 29.8 & 19.1 & 0.65 \\
\hline & Standard value & 26.3 & 2.7 & 0.747 & 28.9 & 18.7 & 0.68 \\
\hline & Standard deviation & 5.797 & 0.019 & 0.168 & 5.712 & 2.535 & 0.175 \\
\hline & Coefficient of variation & 0.228 & 0.007 & 0.233 & 0.192 & 0.133 & 0.27 \\
\hline
\end{tabular}

Table 2. Collected data of standard penetration test in field.

\begin{tabular}{|c|c|c|c|c|c|c|c|c|}
\hline Blow Count(blow) & $\mathbf{2}$ & $\mathbf{3}$ & $\mathbf{4}$ & $\mathbf{5}$ & $\mathbf{6}$ & $\mathbf{7}$ & $\mathbf{8}$ & $\mathbf{9}$ \\
\hline \hline times & 4 & 45 & 37 & 55 & 24 & 9 & 2 & 5 \\
\hline
\end{tabular}

Table 3. Statistical result of natural water content data.

\begin{tabular}{|c|c|c|c|c|c|c|c|}
\hline Natural Water Content & $\mathbf{1 5} \leq \mathbf{W}<\mathbf{2 0}$ & $\mathbf{2 0} \leq \mathbf{W}<\mathbf{2 5}$ & $\mathbf{2 5} \leq \mathbf{W}<\mathbf{3 0}$ & $\mathbf{3 0} \leq \mathbf{W}<\mathbf{3 5}$ & $\mathbf{3 5} \leq \mathbf{W}<\mathbf{4 0}$ & $\mathbf{4 0} \leq \mathbf{W}<\mathbf{4 5}$ & $\mathbf{4 5} \leq \mathbf{W}<\mathbf{5 0}$ \\
\hline \hline number & 8 & 71 & 29 & 14 & 15 & 8 \\
\hline
\end{tabular}

\subsubsection{Calculating Characteristic Value of Bearing Capacity}

Because Binzhou area is mainly located in the Yellow River alluvial plain, silty soil sediments are mostly caused by alluvial deposits [6]. According to the empirical value of Technical Standard for Building Foundation (DB42/2422003) and Base Design Criterion for Construction Foundation (DBJ15-31-2003) [7, 8] in which the formation reasons of silty soil sediment are similar to Binzhou area , the characteristic value of bearing capacity is $129.3 \mathrm{kPa}$ obtained by interpolation.

\subsection{Determining Bearing Capacity of Silty Soil by Soil Test Data}

\subsubsection{Determining Standard Value of Natural Water Content}

\subsubsection{Natural Water Content Data Statistics}

148 natural water content data obtained from the actual project are counted according to the distribution interval, and the statistical results are shown in Table 3.

\subsubsection{Calculation and Analysis of Statistical Data}

Using the statistical results, a data distribution histogram is performed (Fig. 2).

From the above statistical results, natural water content (w) data mainly concentrate in the range of $20 \% \sim 40 \%$, accounting for about $87 \%$ of the total statistical data. The ratio of $\mathrm{w}<20 \%$ and $\mathrm{w}>40 \%$ is smaller. Based on the statistical analysis of the above data, the coefficient of variation $\delta$ is 0.254 , which is larger than the theoretical upper limit of 0.15 . If the data of $\mathrm{w}<20 \%$ and $\mathrm{w}>40 \%$ are eliminated for their obvious deviation, the variation coefficient $\delta=0.148<0.15$ (the theoretical upper limit value of variation coefficient), then the standard value $\Phi_{k}$ is 24.24, maximum value 31.4, minimum value 20.2 , the average value of $\Phi_{\mathrm{m}}=24.84$.

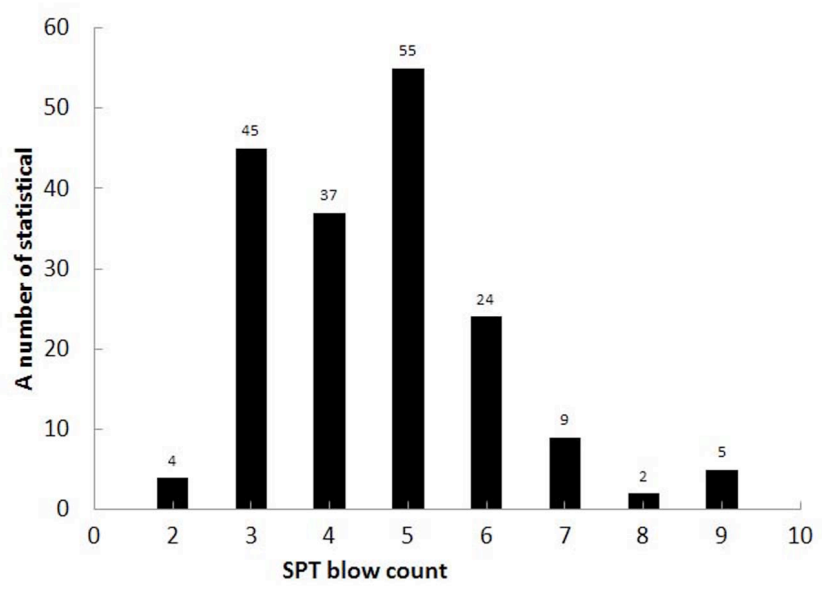

Fig. (1). Number of blows and statistical times of Standard penetration test. 


\subsubsection{Determining Natural Void Ratio Standard Value}

\subsubsection{Statistics of Natural Void Ratio Data}

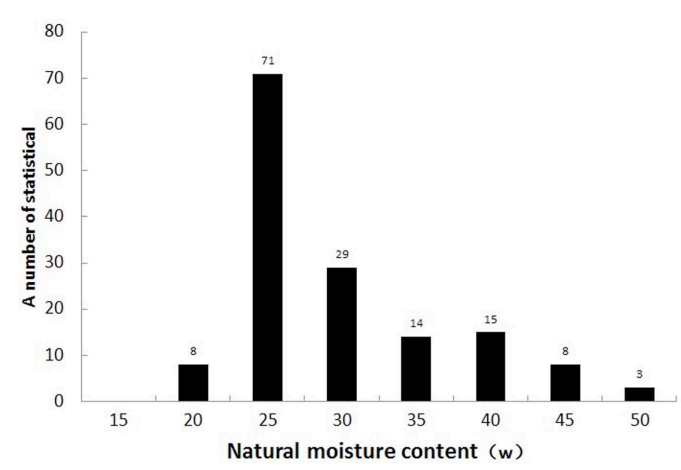

Fig. (2). Statistical histogram of natural water content distribution and number.

According to the distribution of 142 natural void ratio obtained from the actual project, the statistical results are shown in Table 4.

\subsubsection{Calculation and Analysis of Statistical Data}

Using the statistical results, a data distribution histogram is performed (Fig. 3).

From the above statistical results, natural void ratio $(e)$ data mainly concentrate in the range of $0.5 \sim 0.9$, accounting for about $90.8 \%$ of the total data. The ratio of $\mathrm{e}<0.5$ and $\mathrm{e}>$ 0.9 is smaller. Based on the statistical analysis of the above data, the coefficient of variation $\delta$ was 0.202 without deviating from any data and larger than the theoretical upper limit of 0.15 . If the data of $\mathrm{e}<0.5$ and $\mathrm{e}>0.9$ are eliminated for their obvious deviation, the variation coefficient $\delta=0.117$ $<0.15$ (the theoretical upper limit value of variation coefficient), then the standard value $\Phi_{\mathrm{k}}$ is 0.688 , the maximum value 0.889 , the minimum value 0.505 , the average value $\Phi_{\mathrm{m}}=0.698$.

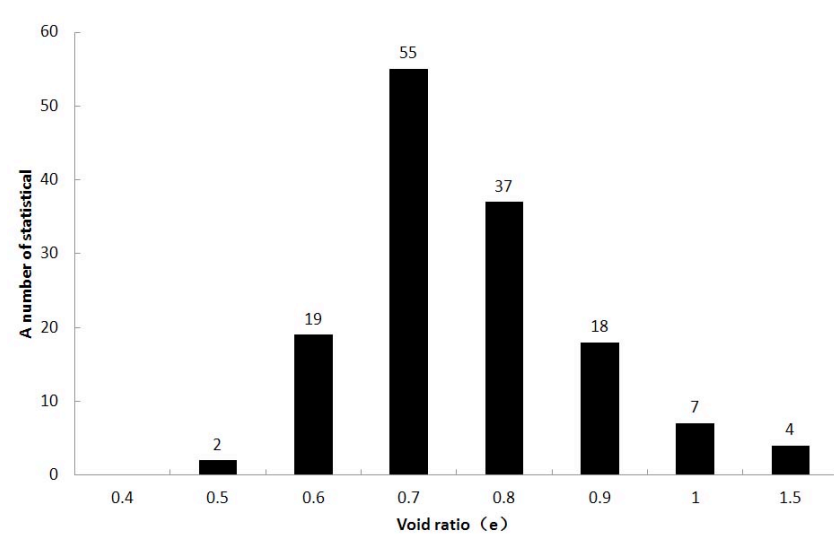

Fig. (3). Statistical histogram of natural void ratio distribution and number.

\subsubsection{Calculating the Characteristic Value of Bearing Capacity}

According to the standard data of the above natural water content and natural void ratio, referring to Technical Specification for Building Foundation (DB42/242-2003) and Base Design Criterion for Construction Foundation (GB 50007-2002) [9], the bearing capacity value of the silty soil obtained by interpolation is $198.2 \mathrm{kPa}$.

\subsection{Determining Bearing Capacity of Silty Soil by Double Bridge CPT}

\subsubsection{Statistics of Double Bridge CPT (Cone Penetration Test) Data}

1095 double bridge CPT data obtained from the actual project are counted according to the distribution interval, and the statistical results are shown in Table $\mathbf{5}$.

\subsubsection{Calculation and Analysis of Statistical Data}

Using the statistical results, a data distribution histogram is performed (Fig. 4).

From the above statistical results, cone tip resistance $\left(q_{c}\right)$ data mainly concentrate in the range of $0.75-2.0$,

Table 4. Statistical result of natural void ratio data.

\begin{tabular}{|c|c|c|c|c|c|c|c|c|}
\hline Void Ratio & $\mathbf{e}<\mathbf{0 . 4}$ & $\mathbf{0 . 4} \leq \mathbf{e}<\mathbf{0 . 5}$ & $\mathbf{0 . 5} \leq \mathbf{e}<\mathbf{0 . 6}$ & $\mathbf{0 . 6} \leq \mathbf{e}<\mathbf{0 . 7}$ & $\mathbf{0 . 7} \leq \mathbf{e}<\mathbf{0 . 8}$ & $\mathbf{0 . 8} \leq \mathbf{e}<\mathbf{0 . 9}$ & $\mathbf{0 . 9} \leq \mathbf{e}<\mathbf{1 . 0}$ & $\mathbf{e}>\mathbf{1}$ \\
\hline \hline Number & 0 & 2 & 19 & 55 & 36 & 13 & 7 & 4 \\
\hline
\end{tabular}

Table 5. Cone tip resistance data collection.

\begin{tabular}{|c|c|c|c|c|c|c|c|c|}
\hline Cone Tip Resistance & $\mathrm{q}_{\mathrm{c}}<0.5$ & $0.5 \leq q_{c}<0.75$ & $0.75 \leq q_{c}<1$ & $1 \leq q_{c}<1.25$ & $1.25 \leq q_{c}<1.5$ & $\begin{array}{c}1.5 \leq q_{\mathrm{c}}< \\
1.75\end{array}$ & $1.75 \leq q_{c} \leq 2$ & $\mathbf{q}_{\mathrm{c}}>\mathbf{2}$ \\
\hline Number & 43 & 47 & 207 & 223 & 190 & 174 & 153 & 58 \\
\hline
\end{tabular}

Table 6. Bearing capacity comparison analysis results.

\begin{tabular}{|c|c|c|}
\hline Method & Standard Penetration & Double Bridge CPT \\
\hline \hline characteristic value of bearing capacity $(\mathrm{kPa})$ & 129.3 & 134.2 \\
\hline
\end{tabular}


accounting for about $86.5 \%$ of total data. The ratio of $\mathrm{q}_{\mathrm{c}}$ $<0.75$ and $\mathrm{q}_{\mathrm{c}}>2$ is smaller. According to the statistical analysis of the above data, the coefficient of variation $\delta$ was 0.617 without deviating from any data and larger than the theoretical upper limit of 0.3 . If the data of $\mathrm{q}_{\mathrm{c}}<0.75$ and $\mathrm{q}_{\mathrm{c}}>$ 2 are eliminated for their obvious deviation, the variation coefficient $\delta=0.267<0.3$ (the theoretical upper limit value of variation coefficient), then the standard value $\Phi_{\mathrm{k}}$ is 1.367 , the maximum value 2 , the minimum value 0.76 , the average value $\Phi_{\mathrm{m}}=1.386$, the data number $\mathrm{n}=918$.

\subsubsection{Calculating Characteristic Value of Bearing Capacity}

Referring to Technical Standard for Building Foundation (DB42/242-2003) and Base Design Criterion for Construction Foundation (DBJ15-31-2003), the characteristic value of bearing capacity obtained by the integrated method is $134.2 \mathrm{kPa}$.

\section{DETERMINATION OF BEARING CAPACITY OF SILTY SOIL}

According to the standard penetration test, soil test and double bridge CPT, Table 6 shows the comparative analysis of bearing capacity.

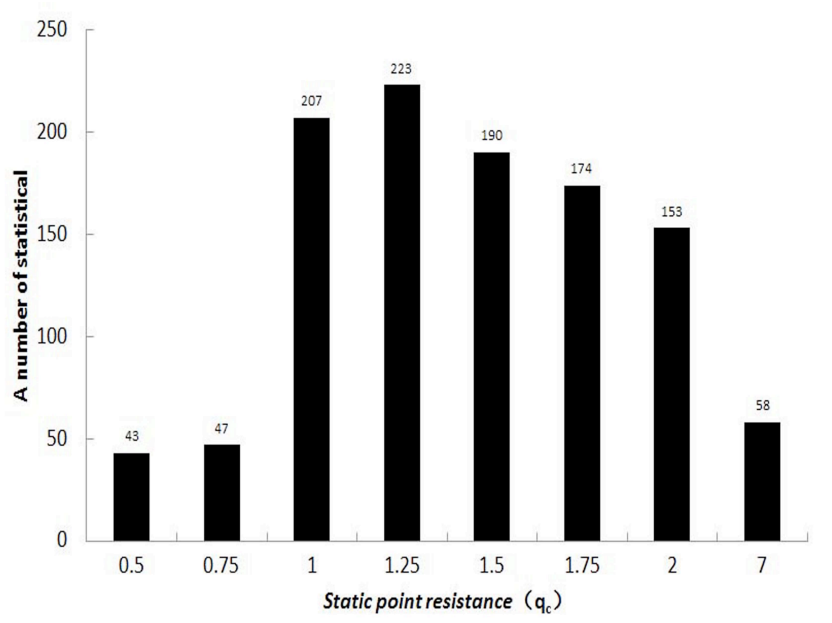

Fig. (4). Statistical histogram of cone tip resistance and number.

From the above table, the eigenvalues of bearing capacity of the silty soil calculated by standard penetration method and double bridge CPT method match better. Therefore, it is more appropriate to take the eigenvalue of silty soil bearing capacity of $130 \mathrm{kPa}$. The recommended value is closer to the current experience in the region, that is, $100 \sim 130 \mathrm{kPa}$. However, the value obtained by soil test is greater than $50 \mathrm{kPa}$

\section{CONCLUSION}

In Binzhou area, standard penetration test and double bridge CPT match better to determinate the bearing capacity of the silty soil. However, the bearing capacity of the silty soil obtained by soil test is greater than $50 \mathrm{kPa}$.

The eigenvalues of bearing capacity is suggested to be $130 \mathrm{kPa}$ that is closer to the empirical value in this area.

The standard penetration test and double bridge CPT should be paid more attention to the silty soil sediment in Binzhou area in the investigation work, which can make a more accurate conclusion.

\section{CONFLICT OF INTEREST}

The authors confirm that this article content has no conflict of interest.

\section{ACKNOWLEDGEMENTS}

This paper is aided by the National Natural Science Foundation (41172222, 41472216) and Science and Technology Development Plan Project of Jinan (201303082).

\section{REFERENCES}

[1] J. G. Wang, "Determination method of bearing capacity of silty soil in zhengzhou area", Journal of Guilin University of Technology, vol. 30, no. 3, pp. 374-377, 2010.

[2] Z. Y. Guo and C. P. Liu, "Determination of bearing of silty soil in Hu aibei, anhui ", Geotechnical Engineering World, vol. 7, no. 3 pp. 38-39, 2004.

[3] H. L. Wei, Y. Z. Yu and S. L. Sun, "Application of static sounding determination of silt, sand carrying capacity", West Exploration Engineering, vol. 9, no.4, pp. 13-14, 1997.

[4] GB50021-2001(2009 ed), Code for Investigation of Geotechnical Engineering, CN: Beijing, pp.131-134, 2010.

[5] Engineering Geology Handbook Edition Committee, Engineering Geology Handbook(4 ${ }^{\text {th }}$ ed),CN: Beijing, pp.332-336, 2002.

[6] X.L.Gu, "Foundation and Basic( $3^{\text {rd }}$ ed)," CN: Beijing, pp.92-93, 2003.

[7] DB42/242-2003, "Base Design Criterion Of Construction Foundation ," CN: Wuhan, pp. 164-166, 2003.

[8] DBJ15-31-2003, "Base Design Criterion Of Construction Foundation," CN: Guangzhou, pp. 30-34, 2003.

[9] GB 50007-2011, "Base Design Criterion Of Construction Foundation," CN: Beijing, pp. 14-16, 2011.

Received: January 15, 2015

Revised: March 28, 2015

Accepted: April 03, 2015

(C) Yunfeng et al.; Licensee Bentham Open.

This is an open access article licensed under the terms of the (https:/creativecommons.org/licenses/by/4.0/legalcode), which permits unrestricted, noncommercial use, distribution and reproduction in any medium, provided the work is properly cited. 